\title{
PLEUROPERITONEAL SHUNTS AND TUMOR SEEDING
}

\author{
Isabelle Baeyens, MD, and Richard G. Berrisford, ChM, FRCS(CTh), Exeter, United Kingdom
}

The Denver pleuroperitoneal shunt (Denver Biomedical, Golden, Colo) has been advocated as an effective and lowmorbidity treatment for recurrent malignant pleural effusions. ${ }^{1,2}$ Respiratory symptoms are effectively palliated in most patients, without any further treatment for their effusion required. Tumor seeding in malignant pleural mesothelioma has been reported for invasive procedures, such as needle thoracocentesis, thoracoscopy, and use of chest tubes. ${ }^{3,4}$ To our knowledge, malignant seeding along the tract of a pleuroperitoneal shunt has not yet been described. The purpose of this case report is to highlight this complication and propose prophylactic irradiation to prevent its occurrence.

Clinical summary. A 76-year-old man with malignant mesothelioma of the left pleura was referred for surgical palliation. He was dyspneic at rest and had anterior chest pain and a persistent cough. Chest x-ray film revealed an extensive left pleural effusion.

A thoracoscopy was performed, and $3 \mathrm{~L}$ of pleural fluid was drained. Both the pleural surfaces and the diaphragm were studded with tumors. On maximal inflation of the lung, the parietal and visceral pleura did not oppose, and therefore a Denver shunt was inserted. At 6 weeks' follow-up, the shunt was performing satisfactorily. At follow-up 9 weeks postoperatively, the subcutaneous tunnel was infiltrated by mesothelioma over a distance of some $15 \mathrm{~cm}$.

Discussion. Tumor growth along the track of a shunt was first reported by van Ooijen and associates..$^{5}$ They presented a case of seeding alongside a peritoneovenous shunt in abdominal malignant mesothelioma and a case of seeding along the track of a Port-A-Cath System (SIMS Deltec, Inc, St Paul, Minn) in pleur-

From the Department of Thoracic Surgery, Royal Devon and Exeter Hospital, Exeter, United Kingdom.

J Thorac Cardiovasc Surg 2001;121:813

Copyright (C) 2001 by The American Association for Thoracic Surgery

0022-5223/2001 $\$ 35.00+0 \quad \mathbf{1 2 / 5 4 / 1 1 1 3 7 7}$

doi: $10.1067 / \mathrm{mtc} .2001 .111377$ al malignant mesothelioma. Lee and colleagues ${ }^{1}$ reported the case of a patient with seeding of the track of a pleuroperitoneal shunt in a series of 20 shunts for malignant effusions, but none of these effusions was related to malignant mesothelioma.

Local radiotherapy has been shown to be effective in preventing tumor seeding in malignant mesothelioma. ${ }^{3,4}$

We describe mesothelioma tracking alongside a pleuroperitoneal shunt, resulting in difficulty locating the chamber and ultimately shunt blockage. This patient had not received prophylactic radiotherapy, although it was our usual policy to irradiate the thoracoscopy port. We now perform early, postoperative, low-dose, local radiotherapy to the site of shunt insertion, which can be different from the site of thoracoscopy ports.

Received for publication Aug 2, 2000; accepted for publication Aug 31, 2000.

Address for reprints: R. G. Berrisford, ChM, FRCS(CTh), Department of Thoracic Surgery, Royal Devon and Exeter Hospital, Exeter EX2 5DW, United Kingdom (E-mail: richard@berrisford.u-net.com).

\section{REFERENCES}

1. Lee KA, Harvey JC, Reich H. Management of malignant pleural effusions with pleuroperitoneal shunting. J Am Coll Surg 1994;178:586-8

2. Petrou BS, Kaplan D, Goldstraw P. Management of recurrent malignant pleural effusions: the complementary role of talc pleurodesis and pleuroperitoneal shunting. Cancer 1995;75:801-5.

3. Low EM, Khoury GG, Matthews AW, Neville E. Prevention of tumour seeding following thoracoscopy in mesothelioma by prophylactic radiotherapy. Clin Oncol 1995;7:317-8.

4. Boutin C, Rey F, Viallat JR. Prevention of malignant seeding after invasive diagnostic procedures in patients with pleural mesothelioma: a randomized trial of local radiotherapy. Chest 1995; 108:754-8.

5. van Ooijen B, Eggermont AM, Wiggers T. Subcutaneous tumor growth complicating the positioning of Denver shunt and intrapleural port-a-cath in mesothelioma patients. Eur J Surg Oncol 1992;18:638-40. 